\title{
Sputum matrix metalloproteinase-9 is associated with the degree of emphysema on computed tomography in COPD
}

Rekha Chaudhuri ${ }^{1}$, Charles McSharry ${ }^{1}$, Mark Spears ${ }^{1}$, Jeffrey Brady ${ }^{2,3,4}$, Christal Grierson ${ }^{2,3,4}$, C Martina Messow ${ }^{5}$, Gino Miele ${ }^{2,3,4}$, Karl Nocka ${ }^{2,3,4}$, William MacNee ${ }^{6}$, Martin Connell ${ }^{6}$, John T Murchison ${ }^{6}$, Michael Sproule?, Omar Hilmi ${ }^{8}$, Douglas K Miller ${ }^{2,3,4}$ and Neil C Thomson ${ }^{1^{*}}$

\begin{abstract}
Background: Matrix-metalloproteinase (MMP)-9 has been implicated in the pathogenesis of COPD, although its link to disease severity is unclear. The purpose of the study was to examine the relationship between disease severity assessed by lung function and computed tomography (CT) and sputum MMP-9 expression, concentration and activity in patients with COPD.

Findings: In 53 COPD subjects, smokers and ex-smokers; 46 healthy controls, smokers and never smokers, we measured sputum MMP-9 concentrations (ELISA) and enzyme activity (FRET), sputum MMP-9 mRNA expression, spirometry, diffusing capacity for carbon monoxide (DLCO) and CT assessment of emphysema (\% low attenuation areas below-950 Hounsfield units).

Sputum MMP-9 concentrations and mRNA expression in COPD subjects were significantly greater than in healthy never-smokers ( $p=0.007$ and $p=0.001$ respectively) and similar to those in healthy smokers. Disease severity when assessed by the extent of emphysema measured by $C T$, but not by spirometry or DLco values, was directly associated with sputum MMP-9 concentrations $[r=0.442(0.171,0.634), p=0.020]$, and MMP-9 activity $[r=0.447(0.219,0.643)$, $p=0.010]$. In moderate to severe COPD, increased MMP-9 mRNA expression levels were associated with reduced post-bronchodilator FEV $1[r=-0.530(-0.686,-0.327), p<0.001], F_{1} / F V C$ ratio $[r=-0.551(-0.701,-0.354), p<0.001]$ and reduced DLCo $[r=-0.399(-539,-0.102), p=0.048]$.
\end{abstract}

Conclusions: Sputum MMP-9 concentrations in COPD are directly associated with the extent of emphysema measured by $C T$ and MMP-9 expression levels are inversely associated with DLco. These findings support a role for MMP-9 in the pathogenesis of COPD.

Keywords: MMP-9, MMP-9 expression, COPD, Computed tomography

\section{Findings}

Inappropriate expression and excessive activity of several matrix metalloproteinases (MMP), including MMP-9 [1,2] has been implicated in the tissue destructive processes associated with chronic lung diseases including COPD [2-7]. Increased sputum MMP-9 protein concentrations and/or activity are reported in current smokers with COPD compared to healthy smokers $[8,9]$. However, a definitive role of MMP-9 in the development of emphysema is uncertain.

\footnotetext{
* Correspondence: neil.thomson@glasgow.ac.uk

${ }^{1}$ Immunology, Institute of Infection, Immunity \& Inflammation, University of Glasgow and Gartnavel General Hospital, Glasgow, Scotland G12 OYN, UK Full list of author information is available at the end of the article
}

For example, mice deficient in MMP-9 develop the same degree of cigarette smoke-induced inflammation and airspace enlargement as control mice and human macrophages MMP-9 mRNA is present in areas of lung irrespective of the presence of emphysema [10]. Nevertheless circulating monocytes from subjects with advanced emphysema on computed tomography (CT) produced more MMP-9 than controls [10]. In previous clinical studies there is a lack of information about concentrations, activities and expression of MMP-9 in well characterized patients with COPD and it is unknown whether MMP-9 activity is linked to disease severity. The aim of the study 
was to test the hypothesis that MMP-9 concentrations and activity in COPD are associated with disease severity as assessed by lung function and computed tomography.

\section{Methods \\ Subjects}

A cross sectional study was performed in subjects with COPD and healthy controls as part of the Glasgow COPD and Asthma Biomarker study [7]. Clinical, physiological and immunological plus imaging (COPD groups only) measurements were performed at baseline. Participants were recruited with mild, moderate and severe COPD (GOLD stages I $(\mathrm{n}=14)$, II $(\mathrm{n}=23)$ and III $(\mathrm{n}=16)$ [11]; (both current smokers and ex-smokers), and healthy smokers and never smokers, defined as volunteers with no known respiratory disease, no chronic respiratory symptoms and normal spirometry.

The West Glasgow Research Ethics Committee approved the study and all patients gave written informed consent.

\section{Measurements}

Spirometry was performed according to American Thoracic Society guidelines [12]. Lung volumes and diffusing capacity for carbon monoxide (DLco) were performed using the body box technique (Zan500 Body Plethysmography, nSpire Health Limited, Hertford, UK). Sputum induction was performed as previously described [7]. CT scans of the Chest were performed at full inspiration using 16 slice Brightspeed and 64 slice Lightspeed (GE CT scanner, Milwaukee, Wisconsin, USA) with the following parameters: $120 \mathrm{KV}, 100 \mathrm{mAs}$, collimation $1 \mathrm{~mm}$, reconstruction slice thickness $0.65 \mathrm{~mm}$, reconstruction slice separation $0.5 \mathrm{~mm}$, pitch of 1 and the data was reconstructed with a CHST filter. All scans were evaluated centrally at the University of Edinburgh. Emphysema was quantified as the percentage of lung CT voxels below a threshold of -950 Hounsfield Units-\% low attenuation areas (LAA)-950, using the software Pulmonary Workstation 2.0 (VIDA Diagnostics, Iowa City, IA, USA) as described previously [13-15]. MMP-9 ELISA and MMP-9 activity kits (fluorescence resonance energy transfer (FRET) method) were supplied by R\&D Systems Europe Ltd. (Cat. Nos. DMP900 and F9M00 respectively; Abingdon, UK). Assays were performed in accordance with the instructions provided; however the activity assay was read kinetically over 4 hours as this showed better reproducibility than an end-point read-out. Samples were not chemically activated with amino-phenyl mercuric acetate to allow estimation of endogenous enzyme activity. The MMP-9 assays were validated for sputum. Samples spiked with exogenous MMP-9 (Lot\#40011-70; Wyeth, USA) showed bias of $<11 \%$ with $101-110 \%$ recovery; inter-assay CV was $<8.8 \%$ and intraassay $\mathrm{CV}$ was $<7.9 \%$; concentrations were stable up to 5 freeze-thaw cycles. Sputum cell MMP-9 expression levels
(Affymetrix number 203936_s_at, on U133 + 2 chips) were measured in RNA isolated from airway inflammatory infiltrate cells harvested from induced sputum in healthy never smokers $(n=15)$, healthy smokers $(n=13)$, smokers with moderate to severe COPD $(\mathrm{n}=15)$ and ex-smokers with moderate to severe COPD $(n=12)$. Expression levels were compared after global normalisation.

\section{Analysis}

Variables were summarised as median (inter-quartile range). Values were compared between patient subgroups using two-sample Wilcoxon tests or KruskalWallis test. Associations of MMP-9 with biomarkers were assessed using Spearman rank correlation coefficient with bootstrap 95\% confidence intervals. All analyses were carried out in $\mathrm{R}$ version 2.11.0 [16].

\section{Results}

\section{Baseline demographics}

Demographics and baseline characteristics are previously reported [7]. Briefly, median (IQR) age [years] of COPD volunteers was $65(61.2,68.9)$, healthy never smokers 49.9 (42.1, 55.8) and healthy smokers 53.3 (45.1, 57.8). In healthy never smokers $\mathrm{FEV}_{1} \%$ predicted median (IQR) was $105.5(95.2,115.0)$ and in healthy smokers this was $92.5(87.5,100.2)$. Lung function in the COPD group was as follows: median (IQR) post-bronchodilator $\mathrm{FEV}_{1} \%$ predicted, 65.0 (48.0-80.0); post-bronchodilator $\mathrm{FEV}_{1} / \mathrm{FVC}$ ratio, 64.0 (50.0-67.0); $\mathrm{DL}_{\mathrm{CO}} \%$ predicted, 60.0 (47.5-70.0).

\section{Sputum MMP-9 concentrations and activity}

Sputum MMP-9 concentrations were increased in COPD subjects compared to healthy never smokers $(\mathrm{p}=$

Table 1 Sputum MMP-9 concentrations and activity in sputum fluid from patients with COPD and healthy controls [Median (IQR)]

\begin{tabular}{|c|c|c|c|}
\hline & & MMP-9 (ng/mL) & MMP-9 activity (ng/mL) \\
\hline \multirow{4}{*}{$\begin{array}{l}\text { Healthy } \\
\text { Control }\end{array}$} & All & $49.80(26.35,136.50)$ & $18.90(12.50,38.35)$ \\
\hline & Never smoker & $34.05(24.45,131.00)$ & $16.60(12.50,28.42)$ \\
\hline & Smoker & $69.00(38.65,184.00)$ & $18.90(13.40,46.45)$ \\
\hline & p value ${ }^{1}$ & $p=0.161$ & $p=0.285$ \\
\hline \multirow[t]{8}{*}{ COPD } & All & $137.50(45.52,362.95)$ & $26.65(12.50,51.85)$ \\
\hline & Ex-smoker & $214.75(101.12,445.05)$ & $42.10(26.02,116.10)$ \\
\hline & Smoker & $56.10(28.90,190.70)$ & $12.50(12.50,32.52)$ \\
\hline & p value ${ }^{2}$ & $p=0.002$ & $p<0.001$ \\
\hline & p value ${ }^{3}$ & $p=0.007$ & $p=0.187$ \\
\hline & p value ${ }^{4}$ & $p=0.343$ & $p=0.787$ \\
\hline & $p$ value ${ }^{5}$ & $\mathrm{p}<0.001$ & $p<0.001$ \\
\hline & $p$ value ${ }^{6}$ & $p=0.617$ & $p=0.086$ \\
\hline
\end{tabular}

${ }^{1}$ Healthy smokers vs. healthy never smoker; ${ }^{2}$ COPD smokers vs COPD ex-smokers; ${ }^{3}$ All COPD subjects vs. healthy never smokers; ${ }^{4}$ All COPD subjects vs. healthy smokers;

${ }^{5}$ COPD ex-smokers vs. healthy never smokers; ${ }^{6}$ COPD smokers vs. healthy smokers. 


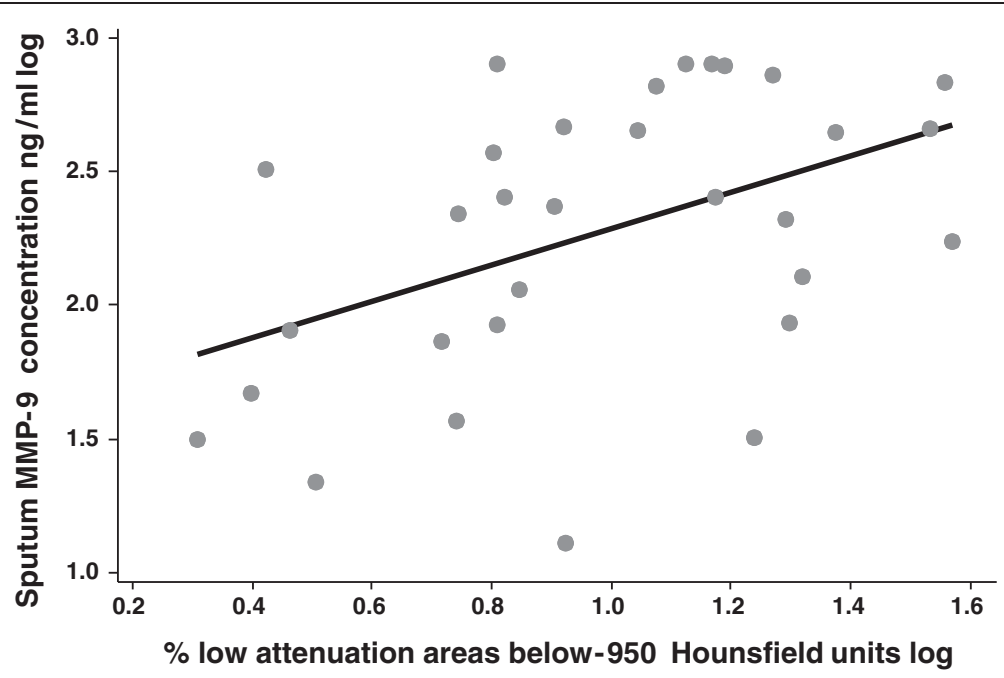

Figure 1 Correlation of sputum MMP-9 concentration $(\mathrm{ng} / \mathrm{ml})$ with computed tomography measure of emphysema [the low attenuation areas below -950 Hounsfield Units taken as an index of emphysema (\% LAA -950) $[r=0.442(0.171,0.634), p=0.020)]$.

0.007), but were similar to healthy smokers $(\mathrm{p}=0.343)$ (Table 1). Sputum MMP-9 enzyme activity was increased in ex-smokers with COPD compared to healthy never smokers $(\mathrm{p}<0.001)$. Ex-smokers with COPD had higher concentrations and activity of sputum MMP-9 than current smokers with COPD $(\mathrm{p}=0.002$ and $\mathrm{p}<0.001$ respectively). Sputum MMP-9 concentrations and activity did not differ significantly between mild, moderate and severe COPD groups (data not shown). The MMP-9 protein concentration and activity did not correlate significantly with $\mathrm{FEV}_{1}$ or DLco\% predicted. The extent of emphysema (\% LAA -950) was significantly associated with sputum MMP-9 protein concentration $[\mathrm{r}=0.442$ (0.171, 0.634), $\mathrm{p}=0.020$ ) ] (Figure 1 ) and MMP-9 activity $[\mathrm{r}=0.447 \quad(0.219,0.643), \mathrm{p}=0.010]$. Sputum MMP-9 protein concentration, $\mathrm{r}=0.724 \quad(0.557,0.839), \quad \mathrm{p}<$ 0.001)$,$] and MMP-9 activity, \mathrm{r}=0.682(0.520,0.800), \mathrm{p}<$ 0.001 , were associated with the percentage of sputum neutrophils. The sputum MMP-9 protein concentration correlated with sputum cell MMP-9 mRNA expression $[\mathrm{r}=0.510(0.292,0.664), \mathrm{p}<0.001]$.

\section{Sputum MMP-9 mRNA expression}

Sputum cell MMP-9 expression levels [median (IQR)] normalized fluorescent intensity units]) were significantly greater in ex-smokers with COPD, [4622 (3161, 5962)], current smokers with COPD, [5085 $(4378,9338)]$ and healthy smokers, [4111 $(1623,6202)]$ compared with healthy never smokers, [1650 (1023, 3443)]; ( $p=0.001$ for each). Sputum MMP-9 expression levels correlated

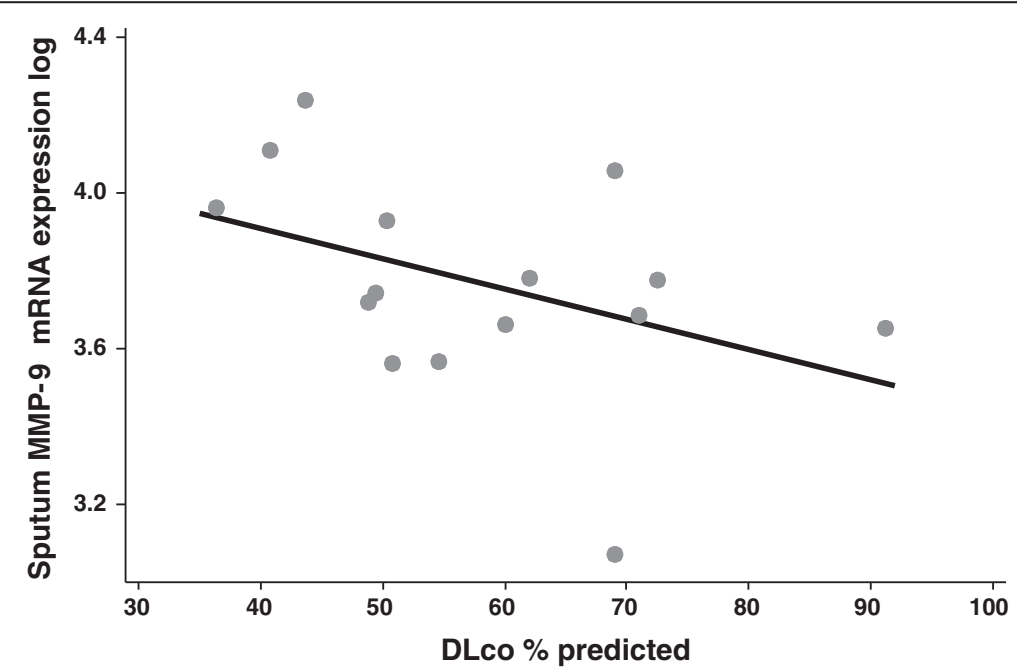

Figure 2 Correlation of sputum MMP-9 mRNA expression and diffusing capacity for carbon monoxide (DLco) $\%$ predicted $[r=-0.399$ $(-0.539,-0.102), p=0.048]$. 
negatively with post-bronchodilator $\mathrm{FEV}_{1} \%$ predicted $[\mathrm{r}=-0.530, \quad(95 \% \mathrm{CI}-0.686,-0.327), \mathrm{p}<0.001]$, postbronchodilator $\mathrm{FEV}_{1} / \mathrm{FVC}[(\mathrm{r}=-0.551(-0.701,-0.354], \mathrm{p}<$ $0.001]$, and DLco [ $r=-0.399(-0.539,-0.102), p=0.048]$, (Figure 2 ) but were not significantly associated with the CT extent of emphysema $[r=0.266(-0.020,0.446), p=0.115]$.

\section{Discussion}

This study found that sputum MMP-9 concentrations and mRNA expression in COPD are significantly greater than in healthy never-smokers, that sputum MMP-9 concentrations are directly associated with the extent of emphysema measured by $\mathrm{CT}$ and that higher $M M P-9$ expression levels are associated with greater airflow obstruction and reduced diffusing capacity. Taken together, these findings provide indirect evidence for a link between MMP-9 and disease severity in COPD.

Previous studies have reported increased MMP-9 protein concentrations and/or activity in current smokers with COPD compared to healthy smokers [8,9]. In contrast to the finding from these studies we found that sputum MMP-9 concentrations and activity in COPD subjects were similar to healthy smokers. There are differences in the severity of disease and smoking status between these studies. The patients with COPD studied previously $[8,9]$ had in general more severe disease compared to the participants in our study, which could explain the different results [17]. Both current and ex-smokers with COPD were recruited to the present study, whereas previous studies included only current smokers with COPD $[8,9]$. Smoking status is however unlikely to explain the different results as ex-smokers had higher MMP-9 levels and activity than current smokers with COPD. The ex-smokers with COPD in the present study had more severe disease, as assessed by the extent of emphysema on CT, which may explain the higher sputum MMP-9 concentrations in this group.

The severity of COPD, when assessed by the extent of emphysema on CT scanning, but not by spirometry values, was significantly associated with sputum MMP-9 concentrations and activity. We found no significant association between sputum MMP-9 levels and DLco; although the extent of emphysema measured by CT often correlates with DLco in COPD, this association is not always found. The findings of an association of greater MMP-9 expression in moderate to severe disease with greater airflow obstruction and reduced diffusing capacity as well as more extensive emphysema on CT scanning with MMP-9 concentrations suggests a role for MMP-9 in the pathogenesis of emphysema. Alternatively, increased sputum MMP-9 may be a marker of disease severity in patients who already have emphysema. Long-term clinical trials of MMP-9 inhibitors in COPD would help establish whether blocking MMP-9 activity attenuates the development and progression of emphysema. Previously, we reported that sputum MMP-12 concentrations and activity in patients with COPD are directly associated with the extent of emphysema measured by CT [7] suggesting that blocking both MMP-9 and MMP-12 may be more effective than inhibiting either MMP-9 or MMP-12 alone.

In conclusion, disease severity in COPD when assessed by the extent of emphysema measured by $\mathrm{CT}$ is directly associated with sputum MMP-9 concentrations. Interventions directed at inhibiting MMP-9 activity, either alone or in combination with MMP-12 blockers, should be investigated for their potential to attenuate the development or progression of emphysema.

\section{Competing interest}

Jeffrey Brady and Gino Miele were employees of Wyeth Pharmaceuticals at the time of the study, and are currently employed by Epistem Ltd and AxisShield respectively.

Karl Nocka is an employee of Pfizer and owns stock in the company. There is no financial gain to the company expected through publication of this manuscript.

Douglas Millar: At the time when this work was performed was an employee and stockholder of Pfizer, who gave financial support for the study.

Neil Thomson has participated in advisory boards and/or received consultancy fees from Asmacure, Chiesi and Respivert. He has received lecture fees from AstraZeneca, Boston Scientific, Chiesi, Glaxo SmithKline and Novartis; industry-sponsored grant funding to the University of Glasgow from Aerovance, Asthmatx, AstraZeneca, Centocor, Genentech, Glaxo SmithKline, Medlmmune, Novartis, Pfizer, Respivert and Synairgen for participating in clinical trials.

Rekha Chaudhuri, Charles McSharry, Mark Spears, Martin Connell, Christal Grierson, C Martina Messow, William MacNee, John T Murchison, Michael Sproule, Omar Hilmi have no competing interests related to this manuscript.

\section{Authors' contributions}

Conception and design: RC, CMCS, DM, NCT. Analysis and interpretation: RC, CMCS, JB, CG, GM, KN, CMM, MS, WMCN, MC, JTM, MS, OH, DM, NCT. Drafting the manuscript for important intellectual content: RC, CMCS, MS, NCT. All authors read and approved the final manuscript.

\section{Acknowledgements}

This work was funded by an award (INF-GU-090) from the Translational Medicine Research Collaboration - a consortium made up of the Universities of Glasgow, Edinburgh, Aberdeen and Dundee and the four associated NHS Health Boards (Greater Glasgow \& Clyde, Lothian, Grampian and Tayside), Scottish Enterprise and Pfizer (formerly Wyeth) and supported financially by NHS Research Scotland (NRS), through the Scottish Primary Care Research Network. The authors would like to thank Joyce Thompson, Jane Lafferty, Maureen Brannigan and Kathleen Masterson for sample collection and Lisa Jolly and lona Donnelly for processing the samples.

\section{Author details}

${ }^{1}$ Immunology, Institute of Infection, Immunity \& Inflammation, University of Glasgow and Gartnavel General Hospital, Glasgow, Scotland G12 OYN, UK.

${ }^{2}$ Pfizer Research/Translational Medicine Research Collaboration, Dundee, UK. ${ }^{3}$ Pfizer Research/Translational Medicine Research Collaboration, Cambridge, MA, USA. ${ }^{4}$ Pfizer Research/Translational Medicine Research Collaboration, Collegeville, PA, USA. ${ }^{5}$ Robertson Centre for Biostatistics, University of Glasgow, Glasgow, UK. ${ }^{6}$ MRC Centre for Inflammation Research, Medical Physics and Clinical Radiology, University of Edinburgh, Edinburgh, UK. ${ }^{7}$ Radiology Department, Gartnavel General Hospital, Glasgow, UK. ${ }^{8}$ Ear Nose and Throat Department, Gartnavel General Hospital, Glasgow, UK.

Received: 16 April 2013 Accepted: 24 May 2013

Published: 6 June 2013

\section{References}

1. Boschetto P, Quintavalle S, Zeni E, Leprotti S, Potena A, Ballerin L, Papi A, Palladini G, Luisetti M, Annovazzi L, et al: Association between markers of emphysema and more severe chronic obstructive pulmonary disease. Thorax 2006, 61:1037-1042. 
2. Elias JA, Kang MJ, Crouthers K, Homer R, Lee CG: State of the art. Mechanistic heterogeneity in chronic obstructive pulmonary disease: Insights from transgenic mice. Proc Am Thorac Soc 2006, 3:494-498.

3. Demedts IK, Brusselle GG, Bracke KR, Vermaelen KY, Pauwels RA: Matrix metalloproteinases in asthma and COPD. Curr Opin Pharmacol 2005, 5:257-263.

4. Elkington PTG, Friedland JS: Matrix metalloproteinases in destructive pulmonary pathology. Thorax 2006, 61:259-266.

5. Gueders MM, Foidart J-M, Noel A, Cataldo DD: Matrix metalloproteinases (MMPs) and tissue inhibitors of MMPss in the respiratory tract: Potential implications in asthma and other lung diseases. Eur J Pharmacol 2006, 533:133-144.

6. Lavigne MC, Thakker P, Gunn J, Wong A, Miyashiro JS, Wasserman AM, Wei S-Q , Pelker JW, Kobayashi M, Eppihimer MJ: Human bronchial epithelial cells express and secrete MMP-12. Bioch Biophy Res Commun 2004, 324:534-546.

7. Chaudhuri R, McSharry C, Brady J, Donnelly I, Grierson C, McGuinness S, Jolly L, Weir CJ, Messow CM, Spears M, et al: Sputum matrix metalloproteinase12 in patients with chronic obstructive pulmonary disease and asthma: Relationship to disease severity. J Allergy Clin Immunol 2012, 129:655-663.

8. Lowrey GE, Henderson N, Blakey JD, Corne JM, Johnson SR: MMP-9 protein level does not reflect overall MMP activity in the airways of patients with COPD. Resp Med 2008, 102:845-851.

9. Culpitt SV, Rogers DF, Traves SL, Barnes PJ, Donnelly LE: Sputum matrix metalloproteases: Comparison between chronic obstructive pulmonary disease and asthma. Resp Med 2005, 99:703-710.

10. Atkinson JJ, Lutey BA, Suzuki Y, Toennies HM, Kelley DG, Kobayashi DK, ljem WG, Deslee G, Moore CH, Jacobs ME, et al: The role of matrix metalloproteinase-9 in cigarette smoke-induced emphysema. Am J Respir Crit Care Med 2011, 183:876-884.

11. Global strategy for diagnosis, management, and prevention of COPD. 2010. http://www.goldcopd.com.

12. Miller MR, Hankinson J, Brusasco V, Burgos F, Casaburi R, Coates A, Crapo R Enright $P$, van der Grinten CPM, Gustafsson P, et al: ATS/ERS task force standardisation of lung function testing: Standardisation of spirometry. Eur Respir J 2005, 26:319-338.

13. Mair G, Miller JJ, McAllister D, Maclay J, Connell M, Murchison JT, MacNee W: Computed tomographic emphysema distribution: Relationship to clinical features in a cohort of smokers. Eur Respir J 2009, 33:536-542.

14. Matsuoka S, Yamashiro T, Washko GR, Kurihara Y, Nakajima Y, Hatabu H: Quantitative ct assessment of chronic obstructive pulmonary disease1. Radiographics 2010, 30:55-66.

15. Coxson HO, Mayo J, Lam S, Santyr G, Parraga G, Sin DD: New and current clinical imaging techniques to study chronic obstructive pulmonary disease. Am J Respir Crit Care Med 2009, 180:588-597.

16. R: A language and environment for statistical computing. 2012. http://www.Rproject.org.

17. Ilumets H, Rytilä P, Demedts I, Brusselle G, Sovijärvi A, Myllärniemi M, Sorsa T, Kinnula V: Matrix metalloproteinases $-8,-9$ and -12 in smokers and patients with stage 0 COPD. Int J Chron Obstruct Pulmon Dis 2007, 2:369-379.

doi:10.1186/2213-0802-1-11

Cite this article as: Chaudhuri et al:: Sputum matrix metalloproteinase-9 is associated with the degree of emphysema on computed tomography in COPD. Translational Respiratory Medicine 2013 1:11.

\section{Submit your manuscript to a SpringerOpen ${ }^{\odot}$ journal and benefit from:}

- Convenient online submission

- Rigorous peer review

- Immediate publication on acceptance

- Open access: articles freely available online

- High visibility within the field

- Retaining the copyright to your article

Submit your next manuscript at $\gg$ springeropen.com 